\title{
Documentação e Informação no Contexto Museológico
}

\author{
Documentation and Information in Museological Context
}

Ednaldo Soares ${ }^{1}$

\section{RESUMO}

Estudantes e acadêmicos de Museologia concordam que a comunicação do museu direcionada ao público fica a desejar, comprometendo sua eficiência e eficácia. Ora usa o jargão da área, ora (mesmo quando esse é evitado) a linguagem não se adéqua aos diferentes públicos: estudantes de nível fundamental, médio, ou universitário etc. Este ensaio propugna por uma reflexão sobre comunicação museológica a partir de conceitos como documentação e informação, contextualizando-os nesse ambiente. Assume-se como crítica à comunicação desprovida de caráter educativo e por não estar contemplada no plano museológico, sendo mera improvisação de curadores breves ou prolixos.

Palavras-chave: documentação museológica; informação museológica; educação.

\begin{abstract}
Heritage students and scholars agree that museum communication is still far from desired request, and compromises both its effectiveness and efficiency. Much information uses either jargon, or when it is avoided, information language is not suitable to different audiences: elementary, high school or college students etc. This essay advocates for a reflection on museological communication starting from concepts such as documentation and information, contextualized in museum environment. It is assumed as a critique of communication devoid of educational nature and not be contemplated in the museum plan, being mere improvisation of brief or wordy curators.
\end{abstract}

Key words: museological documentation; museological information; education.

\footnotetext{
${ }^{1}$ Mestre e Doutor e pós-doutorando em Administração. Integrante de grupo de pesquisa na EAUFBA.
} 


\section{Introdução}

Documentos ou documentação fazem parte do cotidiano dos indivíduos. De modo geral, eles servem para identificar (pessoas, animais, espécies vegetais e minerais, objetos etc.), mas também para garantir direitos ou estipular obrigações ao amparo de dispositivos de ordem legal, ou mesmo de outras ordens ordinária ou regimentalmente aceitas, tais como: crenças, religiões, associações, agremiações etc. Todavia, é a atribuição de significado oriundo da informação contida no documento / documentação o que lhe confere validade ou valor.

A informação, por seu turno, é expressão de conhecimento adquirido através de experiência ou de estudo (pesquisa). Para Oleto (2006: 57),

Ela [a informação] é imprescindível em qualquer área do conhecimento, especialmente na acadêmica. [...] Le Coadic (1996, p.5) aceita que a informação seja um conhecimento inscrito sob a forma escrita, oral ou audiovisual. Ela comporta um elemento de sentido e é transmitida a um ser consciente por meio de uma mensagem inscrita. Bukland (1991, p. 351-360) [...] identifica três usos principais da palavra informação: informação como processo, informação como conhecimento; informação como coisa. Como processo, a informação muda o conhecimento de alguém e é situacional. [...] A informação como conhecimento tem uma de suas formas quando reduz as incertezas. $\mathrm{O}$ conhecimento comunicado refere-se a algum fato, assunto ou evento dado como notícia, [...] sendo, entretanto, intangível, não podendo ser tocado ou medido. A informação como coisa se refere aos objetos que são considerados como sendo informativos em suas características físicas, tais como o dado e os documentos expressos, descritos ou representados por alguma forma física como o sinal, o texto ou a comunicação desses.

Não obstante esse entendimento acerca da informação, o seu registro é prérequisito e uma responsabilidade de primeira ordem para todos os envolvidos em processos de conservação, gerenciamento de patrimônio e os que desenvolvem sistemas de documentação e/ou estratégias de gerenciamento da informação (LETELLIER, 2007).

Ora, se de um lado existe o consenso de que documento pode ser tanto um pedaço de papel, ou qualquer outro objeto que forneça informação, especialmente de natureza oficial ou legal (COLLINS DICTIONARY, 1994: 460), de outro lado, tem-se que documentação é "the act of supplying with or using documents or references" (Ibid, 
1994: 460), Sendo assim, entende-se documento ou documentação como a resultante da produção de um conhecimento específico.

Em geral, tal conhecimento se volta para o futuro, pois, da parte de quem (indivíduo ou instituição) produz o conhecimento, o ato de documentar está imbuído em uma preocupação direcionada às gerações futuras, ou seja, de que o conhecimento tido hoje a respeito de alguém ou de algo (patrimônio, objeto etc.) possa chegar ao futuro, no mínimo, com informação igual à que foi originalmente documentada. Tratando-se de um processo, com o passar do tempo, a documentação é ordinariamente enriquecida com novos dados (novas informações) a respeito do ser ou do objeto documentado.

É também consensual a noção de que o documento / documentação somente se torna eficaz quando a informação nele contida é comunicada (em diferentes escalas ou profundidades) a públicos distintos. No caso particular do museu, tanto estudantes quanto pesquisadores de Museologia, todos estão de acordo que a comunicação do museu (pelo menos em um considerável número dessas instituições) direcionada aos seus públicos ainda fica muito a desejar. E esse fato tem contribuído para a perda da eficiência e eficácia da comunicação museológica. Isso porque no ato de comunicar, ora há o uso excessivo do jargão ${ }^{2}$ próprio daqueles que trabalham em museu e áreas afins e diz pouco aos visitantes, ora (mesmo quando esse jargão é evitado) a linguagem utilizada para comunicar as informações não se adéqua aos diferentes públicos que visitam os museus, como os estudantes de nível fundamental, de nível médio, ou universitário etc.

Há, no caso do uso de palavras técnicas própria desse ambiente, a falta de catálogo explicativo para visitantes leigos ou ambientalmente neófitos, o que torna as informações das etiquetas junto dos objetos quase uma meta linguagem, ou signo-signo, só decodificada por alguns poucos visitantes. Como se verá mais adiante, para uma

\footnotetext{
${ }^{2}$ A seguinte lista foi retirada das etiquetas junto a objetos de arte expostos em vários museus: "Acrílico, serigrafia e pastel oleoso sobre tela"; "Afresco"; "Aquarela realçada com nanquim sobre papel"; "Aço Cor-Ten"; "Alabastro"; "Ardósia de Delabole"; "Aquarela sobre velino"; "Prata batida, repuxada, cinzelada"; "Encáustica sobre tela"; "Pigmento e resina sintética sobre tela"; "Pedra de Hornton verde"; "Tinta magna sobre tela"; "Pedra Vermelha Mansfield"; "Colagem, giz colorido e carvão sobre papel"; "Água-forte sobre papel"; "Xilogravura policromática sobre papel”; "Litografia sobre papel"; "Terracota esmaltada"; "Iluminura em velino"; "Guache em papel montado sobre tela"; "Têmpera sobre linho"; "Gravura sobre papel"; "Tinta Impervo sobre alumínio"; "Estuque"; "Serigrafia sobre papel"; "Nanquim e aguada sobre papel"; "Pastel sobre pergaminho"; Emulsão sobre tela: "Emulsão de cera sobre tela".
} 
grande maioria dos visitantes de museu, o objeto assume a posição de ser a única informação sobre si mesmo; consequentemente, a leitura das etiquetas é deixada de lado.

Para uma comunicação eficiente, portanto, cabe ressaltar que a produção de documentos / documentação requer um fluxo de trabalho, que inclui: etapas (planejamento, aquisição, armazenamento, processamento, pós-processamento, publicação e disponibilização); equipamentos, programas; formatos de arquivos; e produtos (TORRES, 2016).

Este ensaio propugna por uma reflexão sobre a comunicação museológica a partir dos conceitos de documentação e informação, contextualizando-os no ambiente museológico. Assume-se, destarte, como uma crítica à comunicação desprovida de caráter educativo, cuja preocupação profisssionalizada não tem sido sobremaneira $\mathrm{e}$ devidamente contemplada no plano museológico e, com isso, não deixa de ser mera "improvisação" de curadores breves ou prolixos. Todavia, embora seja extraída do sistema de documentação, essa comunicação nem sempre é condizente com a necessidade de informação que cada (diferente) público de museu precisa para estar em sintonia com o propósito da exposição e aprender com ela, educando-se.

\section{Documento / documentação: categorias}

Dependendo do suporte em que é registrado, o documento pode ser analógico ou digital. Diz-se que o documento é analógico quando seu registro se dá sobre um suporte físico (e.g.: carteira de identidade, certidão de nascimento, certidão de casamento, passaporte, fatura comercial etc.). E diz-se que o documento é de natureza digital quando se the atribuem outras características diferentes do suporte físico, tais como: serial; sequencialidade; numeração; combinação etc.; ou seja, quando lhe são atribuídas características próprias do sistema digital binário, cuja unidade de medida representativa do mundo físico é o "bit", utilizado em computação (mais precisamente nos recursos técnicos - "hardware" e "software" - que, em conjunto com os recursos humanos - 
"pleopleware" - formam uma combinação definidora de um sistema de informação) (ROSA, 2004).

Yates e Summer (1997: 3 apud DAVENPORT, 1999: 2), de maneira resumida, porém precisa, afirmam que

[...] digital documents [...] are to be broadly defined as 'any socially and contextually complete semantic unit of communication - including text, video, audio, hypermedia, multimedia and computer mediated communication - which is created, stored, and transmitted via digital media'.

Ainda com relação aos documentos, eles podem ser classificados em duas outras categorias: (1) conscientes $^{3}$ (PONTANI; SESANA, 2011: 25); e (2) inconscientes ${ }^{4}$ (LANZI, 2011). São chamados de documentos conscientes, todos aqueles portadores de informações especialmente gravadas para serem transmitidas. E são categorizados como documentos inconscientes, os que carregam um significado definido por seu contexto original, advindo da comunicação humana. $\mathrm{Na}$ verdade, esses são documentos materiais ou não, que, neutralmente contêm informações e devem ser assim reconhecidos, a partir de um histórico que lhes atribui um valor testemunhal. Esses documentos carregam informações de maneira inconsciente e, independentemente de quem as tenha registrado, passam a fornecer dados informativos quando são interpretados em conformidade com os mais variados contextos ou ambientes.

Pergunta-se, então: o que é documentação museológica? E, ao mesmo tempo: em que sentido a palavra informação, nesse caso, é utilizada? De acordo com Ferraz (1991), a documentação que diz respeito a acervos museológicos corresponde ao

\footnotetext{
3 “"...] documenti che riportano informazioni [...] che sono in essi annotate volontariamente allo scopo di una comunicazione [...]. I documenti, secondo questa accezione, sono 'scritti' e prescindono dal materiale (il supporto fisico) sul quale lo scritto insiste." (PONTANI; SESANA, 2011:125) ([...] documentos que fornecem informações [...] as quais são neles voluntariamente anotadas com o propósito de comunicar [...] Os documentos, de acordo com essa acepção, são 'impressos' e transcendem o material (o suporte físico) sobre o qual o que está escrito persiste. - Tradução livre do autor).

4 “[...] condizionati da fattori inconsci di varia natura: considerazioni umane nei confronti del soggetto e del futuro osservatore, come anche una serie di variabili più "sottili", quali il gusto, la sensibilità, l'abilità [...] La realtà è troppo vasta per poter essere descritta integralmente: dobbiamo operarvi una selezione, che rappresenta sempre una interpretazione." (LANZI, 2011) ([...] condicionados por fatores inconscientes de vários tipos: considerações humanas em relação ao assunto e ao futuro observador, bem como por um número de variáveis mais "sutis", como gosto, sensibilidade, capacidade [...]. A realidade é imensa para ser descrita integralmente: deve-se fazer uma seleção, que sempre é uma interpretação. Tradução livre do autor).
} 
conjunto de todas as possíveis informações (em palavras e/ou imagens) acerca de cada um dos itens que os compõem. Demais, a pesquisadora acrescenta que essa documentação inclui tanto informações intrínsecas, isto é, aquelas que são "deduzidas do próprio objeto", como informações extrínsecas; ou seja, quando são "obtidas de outras fontes que não o objeto", sendo essas últimas as mais abundantes (FERRAZ, 1991: s/n).

Quanto ao sentido da palavra informação usada no contexto de documentação museológica, entende-se que ela engloba os três sentidos apontados por Bukland (1991: 351-360 apud OLETO 2006: 57), a saber: (1) informação como processo; (2) informação como conhecimento; e (3) informação como coisa.

Enquanto informação como processo, a documentação museológica contribui para que o conhecimento de alguém sobre determinado(s) objeto(s) tenha o seu status modificado (alargado) e, desse jeito, a consequente modificação propicia a redução das incertezas que o indivíduo certamente tinha (ou ainda possa ter) acerca do(s) objeto(s); configura-se, destarte, em informação como conhecimento. Em primeiro lugar, no entanto, tem-se a informação como coisa, isto é, aquela representada pelo próprio objeto em sua forma física e, como tal, oferece ao indivíduo (observador e/ou pesquisador) informações sensoriais sobre si e, ao mesmo tempo, se sujeita a interpretações feitas de maneira contextualizada conforme o "ambiente".

Há, todavia, as críticas de estudiosos referentes ao atraso em que a questão relacionada com a informação / documentação museológica se encontra, mormente quando se faz um paralelo entre esse estado e aquele relativo à "aproximação" do museu com o público. Isso porque, segundo Castro (2009:135), o movimento empreendido pelo museu na direção de seu público é atualmente bastante notório e vital; ao contrário, porém, fato semelhante não se verifica com a mesma vitalidade, no que concerne à busca por mais informação, à feitura primorosa da documentação e ao próprio museu (CASTRO, 2009: 135).

Ora, em se tratando de matéria no âmbito das ciências sociais, a crítica tem sua razão de existir. Até porque 
Historically, the social sciences have been coupled to social criticism. Social theory began, in fact, as an attempt to find footing for criticism - to identify groups who, because of their situation in society, would be able to convert criticism into practice. This was Marxism's achievement, as it was SaintSimon's and, in different way, Weber's. (GITLIN, 1996: 329).

É verdadeiramente notória a movimentação que tem sido feita pelo museu para se aproximar do público. Todavia, esse público nem sempre é exclusivamente público de museu (visitantes de exposições, estudantes ou pesquisadores), mas pessoas que ocasionalmente frequentam ou vêm ao espaço de uma dada instituição museológica não para se relacionar com os objetos de seu acervo. Isso porque, muitas dessas instituições, hoje em dia, locam frações de seus recintos para a ocorrência de eventos casuais das mais diferentes espécies: celebrações de bodas, shows musicais e de danças, apresentações teatrais etc. Outros museus ainda têm em suas dependências espaços locados principalmente para o uso comercial como restaurante ou bares - os chamados "cafés des arts" -, que atraem um público numeroso, mas não necessariamente público de museu.

\section{Museu: a responsabilidade de comunicar e educar}

A public consists of the real individuals who make decisions to use or not certain media materials.

Joseph Turow

Entendido como "um universo de pensar" (CASTRO, 2005: 31), o museu é um agenciário comunicador, caracterizado por sua particular impressão ideológica, a partir da escolha / seleção dos objetos de seu acervo, uma vez que a aquisição dos objetos marca o início do ato de documentar (NASCIMENTO, 1998: 99; STRANSKY, 1989). Sendo assim, o museu tem a obrigação de dar informações cognitivamente inteligíveis para todos aqueles que adentram os espaços onde seus objetos são documentados e/ou expostos.

Para tanto, a documentação que respeita a cada objeto do acervo do museu precisa necessariamente ser atualizada a fim de que, enquanto os objetos permanecerem 
temporária ou permanentemente expostos, ou mesmo acondicionados em a reserva técnica, as informações a seu respeito oriundas da documentação, que são minimamente dadas na exposição, mas expandidamente arquivadas em dossiês, também estejam sempre atualizadas.

Entretanto, conforme menção retro, para que a comunicação da informação se torne eficaz, ela precisa atingir os diferentes públicos de museu, isto é, deve ser compreensivelmente clara, com vistas ao comprometimento e engajamento dos públicos com as exposições. Em outras palavras, a comunicação deve provocar neles (públicos) a busca por um relacionamento estreito entre si e os objetos. Até porque, na verdade, é esse relacionamento (homem-objeto), em confronto com uma dada realidade, o objeto de estudo da Museologia (GUARNIERI, 1990: 7).

Afinal, "New times call for new thinking." (CURRAN, 1996: 82). E porque são novos tempos, o museu precisa repensar o modo de se comunicar com os públicos, já que eles não são uniformes, mas diferenciados, cuja comunicação do museu com cada um deles também exige modos distintos de se comunicar. Além do mais, sabe-se que a construção da documentação precede e é o alicerce da educação museológica. Daí, o necessário empenho e cuidado que se deve ter na elaboração da documentação museológica e, sobremaneira no ato de comunicá-la apropriadamente aos diversos públicos. A comunicação museológica precisa ser devidamente planejada para ser eficaz.

\section{Referências}

BUCKLAND, Michael K. Information as thing. Journal of the American Society for Information Science, v. 42, n. 5, p. 351-360, June 1991.

CASTRO, Ana Lúcia Salinas de. O Museu do Sagrado ao Segredo. Rio de Janeiro: Revan, 2009.

; LOUREIRO, José M. M. O Objeto de Estudo da Museologia. In: GRANATO, M; SANTOS, C. P. dos (orgs.): Museus: Instituição de Pesquisa. Rio de Janeiro: MAST, 2005, 100 p (MAST Colloquia, v.7).

COLLINS ENGLISH DICTIONARY - Updated third Edition. Glasgow: HarperCollins Publishers, 1994. 
CURRAN, James. Mass Media and Democracy: A Reappraisal. In: CURRAN, J.: GUREVITCH, M. (edits.): Mass Media and Society. London: Edward Arnold, 1996.

DAVENPORT, Elisabeth. Groups, Adaptation, Coordination and Translation (GACT): Digital Documents and the Organizational Genome. In: Proceedings of the $32^{\text {nd }}$ Hawaii International Conference on System Sciences, 1999. Disponivel em: https://scholar.google.com.br/scholar?start $=10 \& \mathrm{q}=$ What + are + analogical + and + digital $+\mathrm{d}$ ocuments\%3F\&hl=pt-BR\&as_sdt=0,5. Acesso em: 25 Mar 2016.

FERRAZ, Helena Dodd. Documentação Museológia: Teoria para uma Boa Prática. IV Fórum de Museus do Nordeste, Recife, 1991. Disponível em: http://docslide.com.br/documents/documentacao-museologica-helena-dodd-ferrez.html. Acesso em: 28 Mar 2016.

GITLIN, Todd. The Politics of Communication and the Communication of Politics. In: CURRAN, J.: GUREVITCH, M. (edits.): Mass Media and Society. London: Edward Arnold, 1996.

GUARNIERI, Waldisa Rússio Camargo. Conceito de cultura e sua interrelação com o patrimônio cultural e a preservação. Cadernos Museológicos. Brasília: MinC/Ibram, n. 3, p. 7-12, 1990.

LANZI, Fernando. La Fotografia fra il suo Oggetto e $i$ Riguardanti. Strumento e Documenti, tra Fatti, Archivi e Nuove Frontiere Tecnologiche. Disponivel em: http://www.sociologiaqualitativa.it/fnaq\%20materiale/fanq\%202011\%20materiali/Lanzi fnaq2011.pdf. Acesso em: 20 Mar 2016.

LE COADIC, Yves-François. A ciência da informação. Brasília: Briquet de Lemos Livros, 1996.

LETELLIER, Robin. Recording, documentation, and information management for the conservation of heritage places: guiding principles. Los Angeles: GCI, 2007.

NASCIMENTO, Rosana. A questão teórico-metodológica e suas implicações na documentação museológica, como suporte para uma concepção educativa de Museu, Cadernos de Sociomuseologia, n. 11, 1998.

OLETO, Ronaldo Ronan. Percepção da Qualidade da Informação, Ciência da Informação, Brasília, v. 35, n. 1, p. 57-62, jan./abr. 2006.

PONTANI, Franco; SESANA, Tiziano. Le Determinazioni Quantitative e le Rivelazioni Contabili ( $3^{\text {a }}$ ed.). Milano: EDUCatt, 2011. Disponivel em: https://books.google.com.br/books?id=ZguFAwAAQBAJ\&pg=PA125\&lpg=PA125\&d $\mathrm{q}=$ documenti+consci: + che + sono? \&source $=$ bl\&ots $=\mathrm{t}-$ XZvzX1vT\&sig=SWRD2fgd0moc25sV6dZ5xwUG6Vo\&hl=ptBR\&sa $=X \& v e d=0$ ahUKEwj36IyunI MAhVEEJAKHdLNBp0Q6AEIJDAB\#v $=$ onepag 
e\&q=documenti $\% 20$ consci $\% 3 \mathrm{~A} \% 20 \mathrm{che} \% 20$ sono $\% 3 \mathrm{~F} \& \mathrm{f}=$ false. Acesso em: 20 Mar 2016.

ROSA, Roberto. Sistema de Informação Geográfica. Laboratório de Geoprocessamento do Instituto de Geografia da Universidade Federal de Uberlândia, 2004.

STRANSKY, Zbynekz. Política de aquisição e adaptação às necessidades de amanhã. Cadernos Museológicos, n. 2, 1989.

TORRES, Rodrigo. Técnicas de documentação do patrimônio cultural (Mini curso). Salvador: Museu de Arqueologia e Etnologia da Universidade Federal da Bahia (MAEUFBA), abril/2016.

YATES, S. J.; SUMMER, T. R. Digital genres and the new burden of fixity. In: Proceedings of the Thirteenth Hawaii International Conference on System Sciences, $v$. VI, Digital Documents Track. R. Sprague. Ed. Los Alamitos CA: IEEE Computer Society Press, 1997, p. 3-12. 